Article

\title{
Exploring the Next Wave of Blockchain and Distributed Ledger Technology: The Overlooked Potential of Scenario Analysis
}

\author{
Horst Treiblmaier (D)
}

check for updates

Citation: Treiblmaier, H. Exploring the Next Wave of Blockchain and

Distributed Ledger Technology: The Overlooked Potential of Scenario Analysis. Future Internet 2021, 13, 183 https://doi.org/10.3390/fi13070183

Academic Editors: Spyros Makridakis, Klitos Christodoulou,

Marinos Themistocleous and Elias Iosif

Received: 15 June 2021

Accepted: 14 July 2021

Published: 19 July 2021

Publisher's Note: MDPI stays neutral with regard to jurisdictional claims in published maps and institutional affiliations.

Copyright: (C) 2021 by the author Licensee MDPI, Basel, Switzerland. This article is an open access article distributed under the terms and conditions of the Creative Commons Attribution (CC BY) license (https:// creativecommons.org/licenses/by/ $4.0 /)$.
Department of International Management, Modul University Vienna, 1190 Vienna, Austria; horst.treiblmaier@modul.ac.at

\begin{abstract}
Blockchain is predicted to disrupt industries, economies, and societies. The properties of distributed ledgers allow the creation of immutable data structures that facilitate shared access in real time and enable a plethora of innovative applications. However, blockchain is not a uniform technology but rather a bundle of evolving components whose implications are notoriously hard to predict. At present, it is not clear how current trends will evolve, with technical evolution, legislation, and public policy being three contingency factors that make ongoing disruptive transformations particularly hard to predict. In light of blockchain's potential disruptive impact, it is surprising that scenario analysis has hitherto been largely ignored in academic research. Therefore, in this paper, we introduce the technique, clarify several misconceptions, and provide examples illustrating how this method can help to overcome the limitations of existing technology impact research. We conclude that if applied correctly, scenario analysis represents the ideal tool to rigorously explore uncertain future developments and to create a comprehensive foundation for future research.
\end{abstract}

Keywords: blockchain; distributed ledger technology; scenario analysis; scenario planning; prediction; research design; contingency theory; blockchain transformation model

\section{Introduction}

Blockchain has a short but rather turbulent history. Its fundamental building blocks date back decades and include groundbreaking work related to linked timestamping, digital cash, proof of work, Byzantine fault tolerance (BFT), public keys as identities, and smart contracts [1]. Most noteworthy, the development of these technical cornerstones is far from over, which implies that blockchain has not yet reached its full potential and that external parameters such as regulatory frameworks cannot adapt quickly enough to accommodate the cutting edge.

The first online realization of blockchain was Bitcoin, which is a public and permissionless ledger that, for the first time, provided a solution for the online transfer of value without the reliance on dedicated intermediaries [2]. The immediate impact of the release of the first Bitcoin client in January 2009 was hardly noticeable outside of dedicated computer science communities, and it was only around the middle of the following decade that the business world started to pay attention when a plethora of innovative and disruptive use cases of the technology were suggested [3-5]. Subsequently, several impactful publications triggered a hype that inflated expectations and, around 2017-018, culminated in what some call the blockchain winter. This development was also fueled by the emergence of so-called ICOs (Initial Coin Offerings), which posed an easy and largely unregulated opportunity for fundraising and produced a substantial amount of fraudulent business propositions. As is frequently the case with hype cycles, the downturn eventually bottomed out, and several practitioners and academics have identified interesting legitimate use cases for the technology, leading to soaring adoption rates and market-ready solutions [6,7].

In spite of this ongoing disruptive transformation and the proposition of viable business models, it is still unclear in which direction the technology will evolve, which potential 
applications it can help to create, and what kind of contingency factors (on individual, organizational, and national levels) may foster or hamper its further development. In this regard, blockchain has also been labeled as a double-edged sword [8] that simultaneously brings forth positive and negative consequences; currently, little is known about the (external) factors that might ultimately determine which outcomes prevail.

In 2020, Themistocleous et al. [9] laid out a research agenda that encouraged academics to investigate use cases, identify adoption barriers, and develop solutions to lower these barriers. In a nutshell, they point out that "for academia, the challenge is to adopt a holistic perspective in an attempt to coordinate inter-disciplinary educational and research efforts" (p. 4). Recent comprehensive literature reviews illustrate that blockchain research has emerged as an important topic in numerous academic communities including information systems, finance, supply chain management, production research, and marketing. However, these studies also reveal that the current methodological repository is predominately focused on detailing specific case studies as well as applying qualitative and quantitative methods that focus on ongoing developments and test models based on averaged responses [10-12]. In contrast, research is missing that is well-suited to identify possible development trajectories and contingency factors that will determine and steer future developments. In an environment that is highly erratic and hard to predict, a more nuanced methodological approach might be advantageous. Therefore, we pose the following three research questions:

How can blockchain research be designed, such that it ...

1. is able to detect the most likely future developments (predictive research)

2. identifies extreme developments (both positive and negative) and assesses the likelihood of their occurrence? (exploratory and predictive research)

3. gives useful and practicable recommendations to industry and public institutions (including advisory boards) on how to create solutions that yield positive outcomes? (design science research/action research)

The remainder of this paper is structured as follows. In Section 2, we elaborate on the components and drivers of blockchain transformation and define the relevant terminology needed for the remainder of this paper. In Section 3, we briefly discuss several academic approaches to predicting the future and juxtapose scenario analysis with popular (mainly quantitative) approaches. Section 4 explores in more detail how scenario analysis can serve as the basis for various study designs. Finally, in Section 5, we wrap up our findings and conclude with concrete recommendations for future research.

\section{Identifying and Defining the Components and Drivers of Transformation}

Technological innovations have been shaping the development of humankind ever since the first tools were crafted from wood, bone, or stone. In this respect, blockchain (such as artificial intelligence (AI), Internet of Things (IoT), etc.) is nothing but a further evolutionary steppingstone toward tools that are able to perform certain tasks more efficiently than has been previously possible. Simultaneously, the application of this technology has side effects, which range from intended to unintended and from easy to difficult to predict. In order to be able to better understand the technology and assess its impacts, it makes sense to first unravel the fundamental building blocks and the respective layers of analysis.

\subsection{Technology Perspective}

Blockchain has been labeled both as a revolution [4] and as "one of the most overhyped technologies ever" [13]. While blockchain enthusiasts never tire in praising one potential use case after another, critics frequently point out that centralized systems often produce comparable results with less complexity. A lot of confusion in the ongoing discussion is caused by unclear terminology and failure to recognize that there is no such thing as a uniform blockchain system. Instead, numerous deployments of distributed ledgers vary substantially in their implementation details, such that some of them do not even exhibit a chain-like structure. 
In this context, it makes sense to first clarify the underlying terminology. The International Organization for Standardization [14] provides a comprehensive list of relevant definitions including "distributed ledger technology" (i.e., a "ledger that is shared across a set of DLT nodes and synchronized between the DLT nodes using a consensus mechanism") and "blockchain" (i.e., a "distributed ledger with confirmed blocks organized in an append-only, sequential chain using cryptographic links"). Therefore, DLTs also include blockchains but, to make things simple, in the remainder of this paper, we will only refer to blockchain. In academia, alternative definitions for blockchain tend to also include their intended goals (e.g., "blockchain is a digital, decentralized and distributed ledger in which transactions are logged and added in chronological order with the goal of creating permanent and tamperproof records" (Treiblmaier, 2018, [15] p. 547)).

Most importantly, it is the features of a system that ultimately yield benefits and not blockchain "per se". In this regard, Kannengießer et al. [16] identify six relevant properties of distributed ledgers, namely: flexibility (the degrees of freedom associated with deploying applications and customizing a DLT), opaqueness (the level of untraceability), performance (the accomplishment of tasks), policy (the ability to guide and verify correct operations), practicality (the achievement of goals with respect to social and socio-technical constraints), and security (the uncompromised functioning of the ledger and the integrity of its stored data). They further unravel those properties into 40 characteristics to describe distributed ledgers on a very granular level. Most of the characteristics are not binary (i.e., existent/nonexistent) but rather reflect the current status of development in comparative terms. For example, characteristics such as availability, durability, or fault tolerance can never be perfect but need to be measured on a continuous scale, measuring the level of target attainment. Presumably, it will mostly be researchers with a technical interest who will investigate the development of one or more specific characteristics in close detail.

\subsection{Application Perspective}

From an applied perspective, it is the specific use case or business case that matters. Blockchain as a technology is no longer the main focus of interest, but rather, it is recognized as a potential means to serve various ends. Numerous industry use cases have been detailed in the literature in areas as diverse as the financial industry $[17,18]$, supply chain management [19], healthcare [20,21], marketing [22], art and the music industry [23], or in tourism [24].

On this layer of analysis, it makes sense to abstract from a specific implementation (unless one wants to report a single case study in great detail) and to scrutinize the transformation of business processes or, more broadly, value chains. It will be mostly business researchers that work from this perspective and who need to specify the use case or the application as their focal point of interest. Meanwhile, such an approach can benefit from overlooking details of current technological development, such as the fact that an immutable ledger might not be immutable at all times and under all conditions.

\subsection{Impact Perspective}

On the most abstract level, blockchain is predicted to transform business, economies, and society [25,26]. Again, it is not the technology itself that is responsible for the (assumed) transformation, but rather the sum total of its implementations, which might differ substantially from case to case. In order to get a better understanding of the impact of blockchain on this layer, it is crucial to focus on the respective feature(s) of interest rather than on the technology as such. To give just one example, this could be the immutability of personal data stored on distributed ledgers and their potential clash with privacy legislation such as the General Data Protection Regulation (GDPR) [27]. Conversely, on this layer, it is pointless to measure constructs such as "Ease of Use" or "Usefulness" as applied in the highly popular Technology Acceptance Model (TAM). From an end user perspective, blockchain is a complex technology that is regularly implemented as a backend solution and, from a company perspective, it is not the technology itself that determines individual 
perceptions, but rather the way in which a specific application is implemented. In other words, blockchain is neither "easy to use" nor "hard to use", and such an assessment only makes sense for a specific implementation.

It will be mostly scholars with a broader perspective such as strategic researchers, economists, or sociologists striving to get the "big picture" who will work on this layer of abstraction. For them, neither specific properties of the technology nor specific implications are of particular interest, but rather their combined impact.

\subsection{Contingency Factors}

Blockchain is considered to be a highly disruptive technology that will exert significant impact on businesses, economies, and societies. However, these changes also depend on a multitude of contingency factors that can either serve as enablers or disablers. Under certain circumstances, such factors might even prohibit a successful implementation of the technology, as could be the case with restrictive legislation or the breaking of cryptographic algorithms (as is envisioned by several authors). Therefore, we suggest differentiating contingency factors according to their overall impact (i.e., positive vs. negative) and their likelihood of occurrence (i.e., expected vs. unexpected/highly unlikely). The ability to identify and quantify events that are unexpected or considered to be unlikely is one of the strengths of scenario analysis over other commonly used study designs, in which such events generally go undetected and/or remain unreported.

\subsection{Blockchain Transformation Model}

Figure 1 integrates the aforementioned building blocks into a nomological network. From a technological perspective, blockchain consists of components (i.e., building blocks) that exhibit a wide variety of properties that can be further differentiated by their defining characteristics [16]. From an application perspective, the underlying implementation can be seen as a black box that enables specific use cases or applications. On this layer of abstraction, it is no longer the implementation details that matter but rather the features of the application that provide an advantage over previous solutions. Finally, all innovations exert certain impacts on businesses, economies, or society as a whole, whether for better or worse. From an impact perspective, the details of an application do not matter but rather the consequences of its deployment.

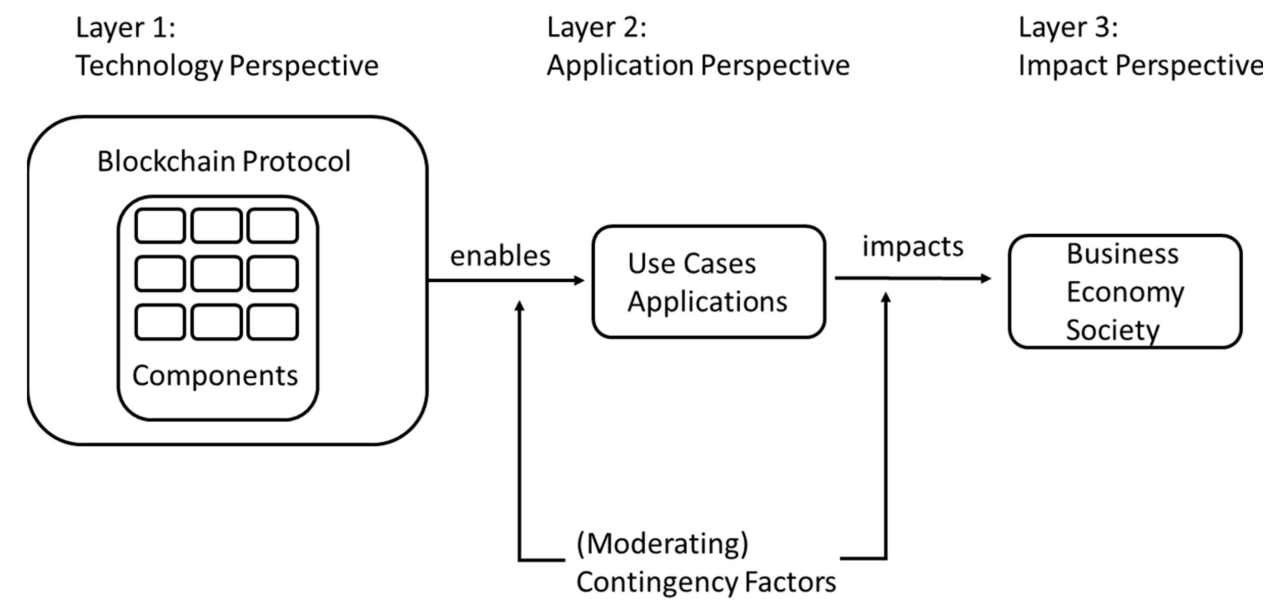

Figure 1. A layered model for blockchain transformation.

Figure 1 also includes contingency factors that we model as moderating variables that affect the enablement of applications and blockchain's broader impact, respectively. These factors include all intended and unintended consequences and side effects that may result from a blockchain implementation as well as so-called black swan events, which are highly unlikely but may yield potentially disastrous consequences. Figure 1 implies that 
each layer constitutes a black box for the next one, and that researchers are not routinely interested in the nuts and bolts of the previous stage. It is the blending of these layers that frequently causes confusion or yields research that lacks relevance for the industry. For example, blockchain by itself does not benefit businesses by motivating consumers (most of whom do not even understand the technology), but rather it is specific applications built on blockchain characteristics (e.g., immutability) which, if marketed properly, can induce a positive effect on buying behavior [28].

Table 1 outlines the generic questions for each respective layer. From a technological perspective, it is crucial to understand how the respective blockchain components will (independently) evolve. For example, this pertains to advances in cryptography, zeroknowledge proofs, or cross-ledger interoperability [29], all of which can substantially transform the technical solutions that can be built upon them. From an application perspective, it is the innovative features of use or business cases that need to be researched, while from an impact perspective, the respective consequences for business, economy, and society deserve further investigation. Contingency factors are an important research area on their own and include topics related to legislation, public policy, and general attitudes toward specific blockchain-based assets such as cryptocurrencies. In this regard, contingency factors can be further divided into enablers, drivers, hindrances, and black swan events.

Table 1. Generic blockchain research questions.

\begin{tabular}{cc}
\hline Layer & Generic Research Question(s) \\
\hline Technology Perspective & How will blockchain components evolve? \\
\hline Application Perspective & What innovative applications can be generated? \\
\hline Impact Perspective & How will business/economy/society be impacted? \\
\hline Contingency Factors & What are context-dependent \\
& enablers/drivers/hindrances/black swan events? \\
\hline
\end{tabular}

\section{Predictive Research}

In 1910, the journalist Arthur Brehmer published a book entitled The World in 100 Years (original version available in German only) in which he gathered numerous prominent authors to envision the world in 2010 [30]. In retrospect, it is especially the predictions of an author called Robert Sloss about the wireless century that are astoundingly precise; Sloss forecasted the possession of personal pocket phones that work at any time in any place and that can even be used for the wireless transmission of pictures (pp. 27-48 in [30]). In comparison, other authors were further off in their predictions that rich colonists would dwell in airships high above Africa or that the exposition to radium would free mankind from all physical ailments. This interesting historical artifact tells us two things. First, prediction of the future is a topic of great interest for a species that actively shapes its environment. Second, in hindsight, some predictions are surprisingly accurate, while others are way off. Was the predictive genius of Robert Sloss based on his ability to extrapolate the research of intellectual giants such as Marconi into the future? Well, maybe. However, it is more likely that the wealth of bold predictions outlined in this book inevitably yielded some that proved more accurate than others. In a way, the retrospective selection of the most precise ones somewhat resembles a " $p$-value" hacking procedure in quantitative research, whereby desirable results are selectively highlighted while others are quietly dropped. While such a procedure might be understandable in light of academic journals' predisposition to publish mostly "successful" research, it does nothing to help to shed light on potential future developments. Therefore, a more rigorous and traceable approach is needed to create research that is verifiable and testable. Scenario analysis provides such an approach that can be extended far beyond merely testing a model's stability [31]. 


\subsection{Theoretical Foundation}

Prediction theories represent one important category in the academic portfolio, next to theories of analysis, explanation, design, and action. Theories that are solely focused on prediction describe what is and what will be and allow the creation of testable propositions, but they regularly do not offer well-developed causal explanations. More comprehensive theories for explanation and prediction describe what is, how, why, when, where, and what will be by providing both causal explanations and testable propositions [32]. Of course, the differentiation between the different types of theory is somewhat permeable since even studies that focus purely on exploration, description, and analysis will be useful only if their results also hold, ceteris paribus, in future situations. Furthermore, it is noteworthy that the overarching theoretical framework does not prescribe a specific methodological approach. Therefore, it makes sense to briefly examine popular methods being used in studies that investigate and predict the impact of technology and to keep in mind that predictive studies do not require a specific theoretical framework.

\subsection{Forecasting Methods}

Outside of rigorous academic research, forecasting can lead to rather bizarre outcomes. In 2017, for example, Adam Jezard predicted on the website of the World Economic Forum that "in 2020 Bitcoin will consume more power than the world does today" [33]. Obviously, such a situation was bound never to happen, since the ever-increasing energy demand by Bitcoin would have raised energy prices significantly, which in turn would have led to a resource allocation to areas that people appreciate more than a cryptocurrency. This misjudgment was caused by the fallacy of extrapolating beyond a reasonable boundary and by ignoring the impact of environmental factors.

In rigorous academic research, predictions are usually better justified, and the most frequently used methods are of a quantitative nature. Of course, numerous judgmental methods such as prediction markets, multiplicative decomposition, expert surveys, and experimentation also exist, but quantitative approaches such as time-series methods or regression models [34] might often be more appealing to showcase academic rigor. Petropoulos and Makridakis [35], to give just one recent example, predict the spread of COVID-19 by using an exponential smoothing model with multiplicative error and multiplicative trend components. The authors in this paper clearly outline their model selection approach (i.e., judgmental) and present different prediction intervals. Research such as this, done in a meticulous manner, is useful to predict the most likely developments and to inform the general public about probable outcomes.

However, there are several goals that cannot be achieved by traditional forecasting methods, even if performed in a rigorous manner. Several well-known but frequently overlooked shortcomings of quantitative modeling and forecasting methods include insufficient sample sizes, lack of content validity, or over-reliance on statistical testing procedures [36]. The same limitations hold for confirmatory approaches that also (implicitly) contain a predictive component in that they imply that certain impacts will also manifest to some extent in the future. However, in the context of this paper, it is more important to mention the neglect of the impact and importance of those events that are considered unlikely or hard to measure in a deterministic manner [37]. After all, the emergence of blockchain itself constitutes an unforeseen event.

Finally, it might be the deterministic nature of frequently used (quantitative) forecasting methods that makes them especially appealing for young aspiring researchers striving to demonstrate their academic prowess. In comparison, approaches such as qualitative techniques, agent-based modeling (ABM) [38], and especially scenario analysis might present greater challenges in demonstrating academic rigor, but this is nonetheless possible if conducted properly. More importantly, these approaches allow for more flexibility and are able to deliver non-deterministic results to complement existing research streams and help to close pending research gaps. 


\subsection{Scenario Analysis}

The planning of scenarios (i.e., descriptions of potential events) helps individuals and organizations to move away from linear thinking and to be able to better cope with external change [39]. Ramirez et al. [40] point out that scenarios "challenge existing assumptions, identify novel lines of inquiry, and enable new research opportunities to emerge" (p. 70). In this paper, we do not differentiate explicitly between scenario planning, scenario thinking, or scenario analysis, but use only the latter term to refer to tools, techniques, and methods that allow organizations to better understand (potential) future developments and to adjust their strategies accordingly. Bradfield et al. [41] point out that scenario planning techniques have been around for several decades and provide an overview of their origins and evolution in long-range business planning. They classify the methodologies into three main schools, namely intuitive-logics models, La Prospective models, and probabilistic modified trend models. This classification illustrates the versatility and coverage of scenario techniques and, from a methodological standpoint, their inclusive nature. The details of the respective approaches are far beyond the scope of this paper and can easily be found in academic as well as practitioner literature [39,42,43], but it is especially their methodological flexibility that is noteworthy and that allows for the straightforward integration of numerous qualitative and quantitative approaches.

Scenario techniques are also capable of exploring the impact of black swan events, which are deemed to be unpredictable or highly improbable yet nonetheless to have massive consequences [38]. Consequently, we argue that exploratory academic research that is not focused on averaging and finding the most likely development or "significant" relationships might be well-suited to identifying such improbable events by leveraging the wisdom of the crowd or dedicated experts. Therefore, blockchain researchers (or researchers who are generally interested in the impact of technology) are well advised to have a closer look at scenario analysis. As a further benefit, this approach can also be used to develop systems or devise strategies with the goal of actively shaping the future. This might be of interest for organizations and policy makers alike.

Figure 2 illustrates a scenario funnel with a timeline starting at the blockchain status quo and the most likely development (the trend scenario) shown as a dotted line. Depending on contingency factors, alternative blockchain scenarios are possible that can either be perceived as positive or negative. Quite naturally, other kinds of alternative scenarios are possible that lie between the respective extreme positions as shown in the figure. While existing research is (implicitly) interested in identifying the trend scenario, a fully fledged scenario analysis will uncover numerous possible developments.

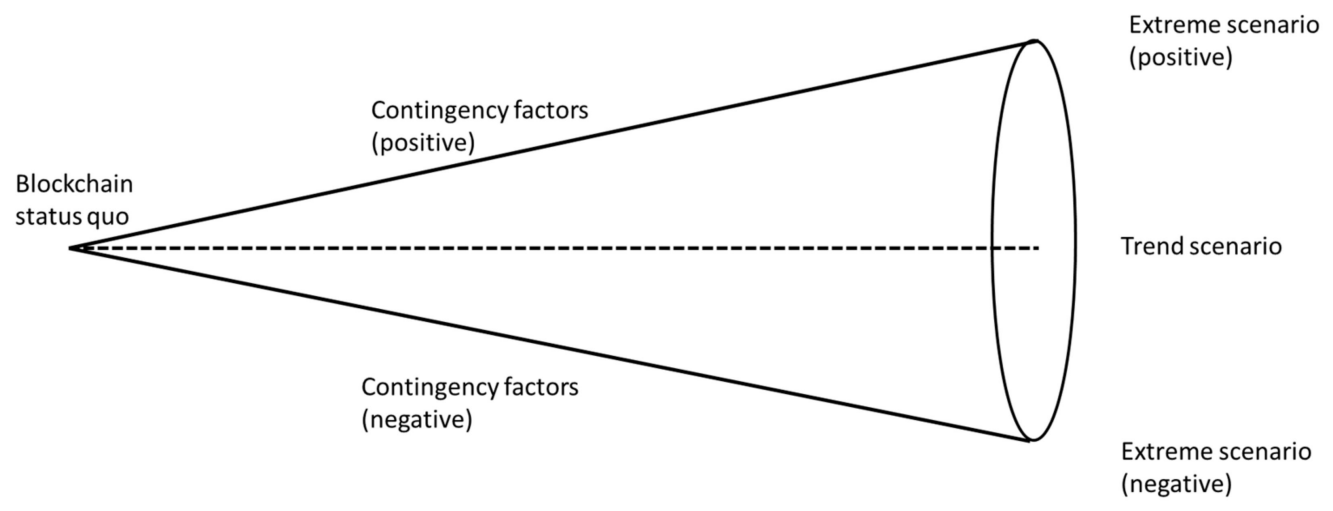

Timeline

Figure 2. Scenario development. 


\section{Scenario-Based Blockchain Research}

The layered blockchain transformation model shown in Figure 1 identifies research topics on various layers, while the scenario funnel shown in Figure 2 provides the corresponding timeline and gives a rough understanding of how a current situation can be extrapolated into a plane of potential outcomes. In this section, we illustrate how a rigorous scenario-based research strategy for future blockchain research can be devised and which research designs might be appropriate.

\subsection{Descriptive Research}

In order to better understand the future impact of blockchain for business, economy, and society, it is crucial to thoroughly describe the technology, its applications, and the existing environment. This can be considered as a preliminary research stage, but in light of the numerous misconceptions surrounding blockchain [44] and a lack of research that identifies contingency factors for successful implementation, a comprehensive descriptive research design constitutes an important academic achievement by itself. For example, the thorough description of the status quo in this stage can be achieved by defining and describing blockchain properties and characteristics according to Kannengießer et al. [16] or by applying a rigorous case study approach according to Treiblmaier [45].

\subsection{Explorative Research}

After having identified the defining properties and characteristics of the status quo (which can be done on a technology, application, or impact level), a scenario analysis approach necessitates the exploration of potential future events. The main difference to other research techniques is that it is not the average effect (in combination with confidence intervals) that is of interest, but rather each potential outcome is of interest-no matter how unlikely. The history of blockchain and its applications is full of events that caused major unwanted disruptions which, in hindsight, could have been avoided relatively easily. For example, the demise of the formerly biggest cryptocurrency exchange Mt. Gox in 2014 was preceded by several security incidents and technical problems that emerged long before the crash. The hack of TheDAO, which led to the draining of 3.6 million ETH and finally the hard fork of the Ethereum blockchain, was preceded by a call for a temporary moratorium and an explicit listing of numerous security attacks and concerns [46].

More recently, a couple of Twitter postings of entrepreneur and business magnate Elon Musk caused wild fluctuation in the exchange rates of cryptocurrencies such as Bitcoin and Dogecoin, illustrating how volatile the cryptocurrency space still is [47]. While academic research, depending on long publication cycles, might not be able to intervene at short notice, it might very well be able to identify extreme scenarios and their underlying causes in the mid and long term. This will help to produce a better understanding of why such events have happened in the past and what can be done to avoid them in the future. In this context, qualitative approaches can help to identify and explore even highly improbable developments. In combination with Delphi studies (see below), such an approach might yield further in-depth insights, since experts might be asked to classify the occurrence probability for events of which they were not even previously aware.

\subsection{Solution Design}

Blockchain is predicted to have a strong impact on our daily lives. Consequently, research in this area also has a particular normative component in that it regularly strives to identify solutions that benefit companies or the general public and advises the industry on how to best implement viable solutions. In this regard, we can broadly differentiate between design science research that is concerned with the development and performance of artifacts [48] and action research, as envisioned by Kurt Lewin, as a broad approach to tackle practical problems [49]. From this perspective, academia is not bound by exploration, description, and prediction, but it can also take an active role in the creation and shaping of businesses, societies, and economies. 
In other words, understanding how a favorable future scenario might evolve can yield interesting insights for managers, politicians, and policy makers of all kinds, and this does not preclude a meticulous scientific approach. Instead, it is the proper documentation of all conducted research steps as well as the applied methodology that ensures the required quality standards and the traceability of the gained knowledge.

\subsection{Impact Assessment}

Assessing the probability of a certain event is an important feature of scenario analysis, and it might be the presumed inaccuracy and arbitrariness of this step that causes a certain amount of suspicion among die-hard quantitative researchers who prefer to rely on the outcomes of Classical Test Theory (CTT) or mathematical frameworks. However, these approaches regularly overestimate the power of CTT and its focus on $p$-values and ignore the capabilities of qualitative approaches or alternative quantitative paradigms such as Item Response Theory, Agent-Based Modeling, or Bayesian inference [36]. Previous articles have already illustrated how future predictions can be based on informed understandings of underlying events, such as the calculation of the relative likelihood that quantum computers will be able to break the underlying cryptographic principles of Bitcoin [50]. By refraining from making exact predictions and relying on distributions instead, a wide array of possible outcomes are taken into account. A fully fledged scenario analysis is also able to offer a wider perspective by including alternative countermeasures such as post-quantum cryptography.

In summary, the assessment of a potential impact can include both the effect of a certain event (in combination with various contingency factors) and the likelihood of its occurrence. From a business perspective, this might help to create risk assessment matrices and to develop strategies to cope with the respective events.

\subsection{Delphi Studies}

As we have already indicated above, one of the biggest strengths of scenario analysis lies in its methodological flexibility and the ease with which it can be integrated into research designs. In this vein, the application of a Delphi study (in which the results of one round are fed back to the participants to get more refined results) can easily be integrated in a scenario study and might help to identify relevant developments and contingency factors as well as the quantification of their impact. Feeding information back to study participants (in most cases, these are domain experts) might trigger a brainstorming process that yields novel insights and leads to the creation of a shared understanding or, alternatively, substantial disagreement when it comes to assessing future impacts of blockchain.

Previous academic studies have already illustrated this potential of a Delphi approach to simultaneously identify the impact of blockchain applications as well their likelihood of occurrence in supply chain management [51] or the expected impact of blockchain in the machine economy in combination with the desirability of certain occurrences [52].

\subsection{A Framework for Scenario-Based Blockchain Research}

Figure 3 integrates the five research designs (upper part), as discussed in the preceding sections and the scenario funnel (lower part). It can be seen how the different designs have varying time orientations. Descriptive research is mainly concerned with investigating the status quo, while explorative research and solution design establish causalities or design products that in the future will meet customers' needs. Predictive methods are used to foresee the anticipated impact of technology and Delphi studies are one methodological approach to provide a feedback loop. The underlying scenario funnel illustrates that as opposed to other methodological approaches, the scenario technique helps to create alternative future developments and allows simultaneously considering positive and negative deviations from the projected path (i.e., the trend scenario).

Table 2 wraps up the approaches discussed above and presents generic research questions as well as exemplary methods, tools, and literature. This list should not be seen 
as exhaustive, but rather as a solid starting point for the further exploration of suitable methods or creative research designs. While the various approaches are presented as a logical sequence, we want to point out that no approach surpasses any other and that rigorous academic research can be conducted at all stages and with all methods.
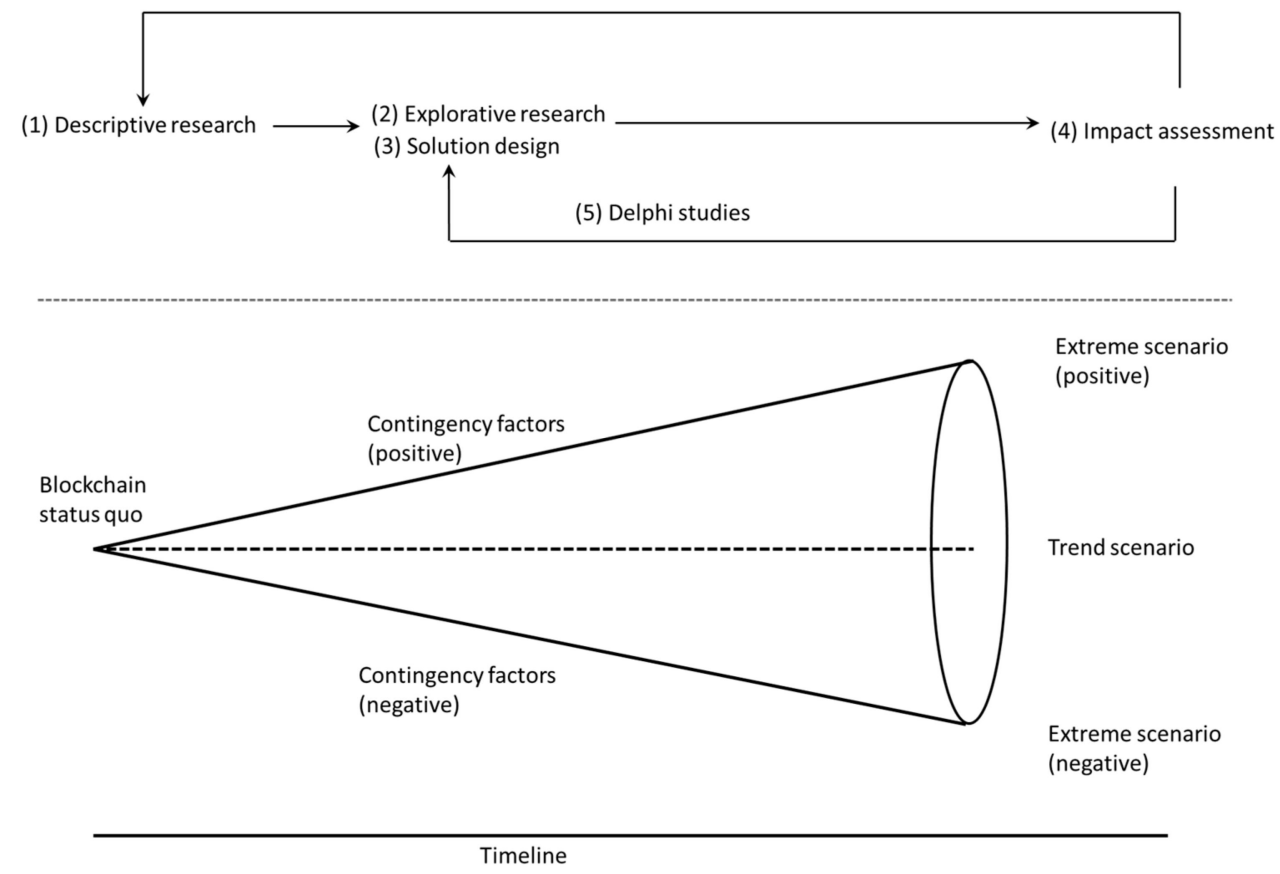

Figure 3. A framework for scenario-based blockchain research.

Table 2. Scenario-based approaches for blockchain research.

\begin{tabular}{cccc}
\hline \multicolumn{1}{c}{ Approach } & Generic Research Question(s) & Exemplary Methods and Tools & Exemplary Literature \\
\hline (1) Descriptive & $\begin{array}{c}\text { What properties (characteristics) does a specific } \\
\text { blockchain application have? } \\
\text { What properties (characteristics) do blockchain-based } \\
\text { tokens have? }\end{array}$ & $\begin{array}{c}\text { Blockchain Properties and } \\
\text { Characteristics Frameworks } \\
\text { Token Classifications }\end{array}$ & {$\left[\begin{array}{c}\text { Which context-specific factors exist? } \\
\text { (2) Explorative }\end{array}\right.$} \\
\hline How likely is the occurrence of specific events? & $\begin{array}{c}\text { Expert Interviews } \\
\text { Content Analysis }\end{array}$ & $\begin{array}{c}\text { Grounded Theory } \\
\text { Regression Techniques }\end{array}$ \\
(3) Impact Assessment & How can context-specific factors shape current trends? & $\begin{array}{c}\text { Structural Equation Modeling } \\
\text { Mathematical Modeling }\end{array}$ & [20] \\
\hline (4) Delphi Studies & Similar to (2) and (3) & Similar to (2) and (3) & [51,52] \\
\hline (5) Solution Design & How can solutions be designed that take different & Design Science & Action Research \\
\hline scenarios into account? &
\end{tabular}

\section{Discussion and Conclusions}

In this paper, we suggest the use of scenario analysis in a rigorous manner to systematically investigate the future impact of blockchain. Previous research in this area has been concerned with identifying adoption barriers and antecedents as well as describing specific applications. Broadening the general research approach by including scenario analysis enables a plethora of interesting and relevant research questions to be addressed and may help fill pending research gaps.

We start off with the suggestion not to treat blockchain as a black box but rather to differentiate between three different perspectives-technology, application, and impactand to also consider relevant contingency factors that might affect future developments. 
The technology itself needs to be unraveled into its respective components to allow for an in-depth investigation of its specific properties and characteristics.

Then, we introduce scenario analysis as an overarching framework that is able to accommodate numerous qualitative and quantitative research methods. Furthermore, we present a couple of research approaches (descriptive, explorative, impact assessment, Delphi studies, solutions design) which can (but do not have to) be combined to tackle the most pending questions of blockchain research in a comprehensive and step-wise manner. The steps do not necessarily have to be carried out in this specific order. Depending on the respective research goal and the overall design, it is possible and often advisable to pursue only one research approach to be able to tackle a specific research question in sufficient detail. The major advantages of this approach can be summarized as follows:

- All important questions pertaining to the future impact of blockchain can be answered in a comprehensive manner without getting stuck in deterministic and confirmatory research designs. This yields plenty of innovative ideas for rigorous research especially for junior faculty and PhD researchers, who will also benefit from getting acquainted with a novel research paradigm.

- Scenario analysis does not preclude an incremental theory-based approach. Quite to the contrary: Rather than focusing on identifying and describing the current situation, the inclusion of future developments might open up new avenues for applying predictive theories to extrapolate current developments.

- The scenario technique framework can be used to embed rigorous research methods, which can be qualitative or quantitative. The same quality standards apply as if those methods would be used in a standalone manner.

- Scenario analysis can take into account black swan events that rarely occur but whose consequences can be dramatic. Recent blockchain history has shown that such occurrences actually happen and that they shape the course of events. While traditional research designs regularly search for the most predictable course of events, scenario analysis strives to identify, explain, and predict such important outliers.

- A research design based on scenario analysis can be highly relevant for the industry, since it can provide specific instructions on how to design solutions. As such, it has a normative component and might help to shape future developments, which might be of relevance for business leaders and policy makers alike.

- Finally, the suggested approach works equally well for other disruptive technologies and can be easily adapted to investigate, for example, the future impact of AI or IoT.

In summary, we believe that the approach that we suggest in this paper, in combination with the framework and the research questions that we derived, will benefit academics by helping them identify interesting blockchain-related research topics and create meticulous research designs. The next wave of disruptive blockchain-based transformation is just around the corner, and scholarly research can be a valuable contribution in predicting and designing the way in which technology shapes our future.

Funding: This research received no external funding.

Institutional Review Board Statement: Not applicable.

Informed Consent Statement: Not applicable.

Data Availability Statement: Not applicable.

Conflicts of Interest: The author declares no conflict of interest.

\section{References}

1. Narayanan, A.; Clark, J. Bitcoin's Academic Pedigree. Commun. ACM 2017, 60, 36-45. [CrossRef]

2. Nakamoto, S. Bitcoin: A Peer-to-Peer Electronic Cash System. 2008. Available online: https://bitcoin.org/bitcoin.pdf (accessed on 10 June 2021).

3. Swan, M. Blockchain: Blueprint for a New Economy, 1st ed.; O’Reilly and Associates: Sebastopol, CA, USA, 2015; ISBN 978-1-49192049-7. 
4. Tapscott, D.; Tapscott, A. Blockchain Revolution: How the Technology Behind Bitcoin Is Changing Money, Business, and the World; Portfolio: New York, NY, USA, 2016; ISBN 978-0-399-56406-2.

5. Iansiti, M.; Lakhani, K.R. The Truth about Blockchain. Harvard Bus. Rev. 2017, 95, 118-127.

6. Treiblmaier, H.; Clohessy, T. (Eds.) Blockchain and Distributed Ledger Technology Use Cases: Applications and Lessons Learned; Progress in IS; Springer International Publishing: Cham, Switzerland, 2020; ISBN 978-3-030-44336-8.

7. Vadgama, N.; Tasca, P. An Analysis of Blockchain Adoption in Supply Chains Between 2010 and 2020. Front. Blockchain 2021, 4. [CrossRef]

8. Niu, B.; Mu, Z.; Cao, B.; Gao, J. Should Multinational Firms Implement Blockchain to Provide Quality Verification? Transp. Res. Part E 2021, 145, 102121. [CrossRef]

9. Themistocleous, M.; Christodoulou, K.; Iosif, E.; Louca, S.; Tseas, D. Blockchain in Academia: Where Do We Stand and Where Do We Go? In Proceedings of the 53rd Hawaii International Conference on System Sciences 2020, Maui, HI, USA, 7-10 January 2020; pp. 5338-5347.

10. Rejeb, A.; Keogh, J.G.; Treiblmaier, H. Leveraging the Internet of Things and Blockchain Technology in Supply Chain Management. Future Internet 2019, 11, 161. [CrossRef]

11. Rejeb, A.; Keogh, J.G.; Zailani, S.; Treiblmaier, H.; Rejeb, K. Blockchain Technology in the Food Industry: A Review of Potentials, Challenges and Future Research Directions. Logistics 2020, 4, 27. [CrossRef]

12. Alkhudary, R.; Brusset, X.; Fenies, P. Blockchain in General Management and Economics: A Systematic Literature Review. Eur. Bus. Rev. 2020, 32, 765-783. [CrossRef]

13. Kharpal, A. Blockchain Is "one of the Most Overhyped Technologies Ever", Nouriel Roubini Says. Available online: https: //www.cnbc.com/2018/03/06/blockchain-nouriel-roubini-one-of-the-most-overhyped-technologies-ever.html (accessed on 16 December 2020).

14. International Standardization Organization ISO 22739:2020(En), Blockchain and Distributed Ledger Technologies—Vocabulary. Available online: https:/ / www.iso.org/obp/ui\#iso:std:iso:22739:ed-1:v1:en (accessed on 5 May 2021).

15. Treiblmaier, H. The Impact of the Blockchain on the Supply Chain: A Theory-Based Research Framework and a Call for Action. Supply Chain Manag. 2018, 23, 545-559. [CrossRef]

16. Kannengießer, N.; Lins, S.; Dehling, T.; Sunyaev, A. Trade-Offs between Distributed Ledger Technology Characteristics. ACM Comput. Surv. 2020, 53, 42:1-42:37. [CrossRef]

17. Grody, A.D. Rebuilding Financial Industry Infrastructure. J. Risk Manag. Financ. Inst. 2017, 11, $34-46$.

18. Gatteschi, V.; Lamberti, F.; Demartini, C.; Pranteda, C.; Santamaría, V. Blockchain and Smart Contracts for Insurance: Is the Technology Mature Enough? Future Internet 2018, 10, 20. [CrossRef]

19. Wang, Y.; Chen, C.H.; Zghari-Sales, A. Designing a Blockchain Enabled Supply Chain. Int. J. Prod. Res. 2021, 59, 1450-1475. [CrossRef]

20. Stafford, T.F.; Treiblmaier, H. Characteristics of a Blockchain Ecosystem for Secure and Sharable Electronic Medical Records. IEEE Trans. Eng. Manag. 2020, 67, 1340-1362. [CrossRef]

21. Bigini, G.; Freschi, V.; Lattanzi, E. A Review on Blockchain for the Internet of Medical Things: Definitions, Challenges, Applications, and Vision. Future Internet 2020, 12, 208. [CrossRef]

22. Rejeb, A.; Keogh, J.G.; Treiblmaier, H. How Blockchain Technology Can Benefit Marketing: Six Pending Research Areas. Front. Blockchain 2020, 3, 1-12. [CrossRef]

23. Owen, R.; O'Dair, M. How Blockchain Technology Can Monetize New Music Ventures: An Examination of New Business Models. J. Risk Financ. 2020, 21, 333-353. [CrossRef]

24. Treiblmaier, H. Blockchain and Tourism. In Handbook of e-Tourism; Xiang, Z., Fuchs, M., Gretzel, U., Höpken, W., Eds.; Springer International Publishing: Cham, Switzerland, 2020; pp. 1-21. ISBN 9783030053246.

25. Treiblmaier, H.; Beck, R. Business Transformation through Blockchain-Volume I/Horst Treiblmaier I Palgrave Macmillan; Palgrave Macmillan: Cham, Switzerland, 2019.

26. Treiblmaier, H.; Beck, R. Business Transformation through Blockchain-Volume II/Horst Treiblmaier I Palgrave Macmillan; Palgrave Macmillan: Cham, Switzerland, 2019.

27. Tatar, U.; Gokce, Y.; Nussbaum, B. Law versus Technology: Blockchain, GDPR, and Tough Tradeoffs. Comput. Law Secur. Rev. 2020, 38, 105454. [CrossRef]

28. Garaus, M.; Treiblmaier, H. The Influence of Blockchain-Based Food Traceability on Retailer Choice: The Mediating Role of Trust. Food Control 2021, 129, 108082. [CrossRef]

29. Sunyaev, A.; Kannengießer, N.; Beck, R.; Treiblmaier, H.; Lacity, M.; Kranz, J.; Fridgen, G.; Spankowski, U.; Luckow, A. Token Economy. Bus. Inf. Syst. Eng. 2021. [CrossRef]

30. Brehmer, A. (Ed.) Die Welt in 100 Jahren; Verlagsanstalt Buntdruck: Berlin, Germany, 1910; ISBN 9783487083049.

31. Erol, I.; Ar, I.M.; Ozdemir, A.I.; Peker, I.; Asgary, A.; Medeni, I.T.; Medeni, T. Assessing the Feasibility of Blockchain Technology in Industries: Evidence from Turkey. J. Enterp. Inf. Manag. 2021, 34, 746-769. [CrossRef]

32. Gregor, S. The Nature of Theory in Information Systems. MIS Q. 2006, 30, 611-642. [CrossRef]

33. Jezard, A. In 2020 Bitcoin Will Consume More Power than the World Does Today. Available online: https://www.weforum.org/ agenda/2017/12/bitcoin-consume-more-power-than-world-2020/ (accessed on 15 May 2021). 
34. Armstrong, J.S.; Green, K.C. Forecasting Methods and Principles: Evidence-Based Checklists. J. Glob. Sch. Mark. Sci. 2018, 28, 103-159. [CrossRef]

35. Petropoulos, F.; Makridakis, S. Forecasting the Novel Coronavirus COVID-19. PLoS ONE 2020, 15, e0231236. [CrossRef] [PubMed]

36. Treiblmaier, H. Taking Feyerabend to the Next Level: On Linear Thinking, Indoctrination, and Academic Killer Bees. SIGMIS Database 2019, 50, 77-94. [CrossRef]

37. Taleb, N.N. The Black Swan; Random House: New York, NY, USA, 2009; ISBN 9780812979183.

38. Treiblmaier, H. The World Isn't Static, So Why Are We? How Agent Based Modeling Helps to Create and Test Dynamic IS Models and Theories. ICIS 2017 Proc. 2017, 3, 1801-1816.

39. Van der Heijden, K. Scenarios: The Art of Strategic Conversation, 2nd ed.; Wiley: Chichester, West Sussex, UK, 2005.

40. Ramirez, R.; Mukherjee, M.; Vezzoli, S.; Kramer, A.M. Scenarios as a Scholarly Methodology to Produce "Interesting Research". Futures 2015, 71, 70-87. [CrossRef]

41. Bradfield, R.; Wright, G.; Burt, G.; Cairns, G.; Heijden, K. The Origins and Evolution of Scenario Techniques in Long Range Business Planning. Futures 2005, 37, 795-812. [CrossRef]

42. Hassani, B.K. Scenario Analysis in Risk Management: Theory and Practice in Finance; Springer: Cham, Switzerland, 2016; ISBN 9783319250564.

43. Blokdyk, G. Scenario Analysis A Complete Guide—2020 Edition; Emereo Publishing: Aspley, Australia, 2021; ISBN 9780655937050.

44. Treiblmaier, H. Blockchain and Tourism: Paradoxes, Misconceptions, and a Research Roadmap. Tour. Econ. 2021. [CrossRef]

45. Treiblmaier, H. Toward More Rigorous Blockchain Research: Recommendations for Writing Blockchain Case Studies. Front. Blockchain 2019, 2, 1-15. [CrossRef]

46. Mark, D.; Zamfir, V.; Sirer, E.G. A Call for a Temporary Moratorium on the DAO. Available online: https://hackingdistributed. com/2016/05/27/dao-call-for-moratorium/ (accessed on 4 June 2021).

47. Dawson, C. Tesla's Musk Renews Critique of Bitcoin, Talks Up Dogecoin. Bloomberg.com. 14 May 2021. Available online: https:// www.bloomberg.com/news/articles/2021-05-13/musk-renews-critique-of-bitcoin-as-environmentally-unsustainable (accessed on 18 July 2021).

48. Sillaber, C.; Waltl, B.; Treiblmaier, H.; Gallersdörfer, U.; Felderer, M. Laying the Foundation for Smart Contract Development: An Integrated Engineering Process Model. Inf. Syst. e-Bus. Manag. 2020. [CrossRef]

49. Lewin, K. Action Research and Minority Problems. J. Soc. Issues 1946, 2, 34-46. [CrossRef]

50. Marchenkova, A. When Can a Quantum Computer Destroy Bitcoin? Available online: https://www.amarchenkova.com/posts/ quantum-computer-bitcoin (accessed on 4 June 2021).

51. Durach, C.F.; Blesik, T.; Düring, M.; Bick, M. Blockchain Applications in Supply Chain Transactions. J. Bus. Logist. 2021, 42, 7-24. [CrossRef]

52. Schweizer, A.; Knoll, P.; Urbach, N.; von der Gracht, H.A.; Hardjono, T. To What Extent Will Blockchain Drive the Machine Economy? Perspectives From a Prospective Study. IEEE Trans. Eng. Manag. 2020, 67, 1169-1183. [CrossRef]

53. Treiblmaier, H. The Token Economy as a Key Driver for Tourism: Entering the Next Phase of Blockchain Research. Ann. Tour. Res. 2021, 103177, 103177. [CrossRef]

54. Clohessy, T.; Treiblmaier, H.; Acton, T.; Rogers, N. Antecedents of Blockchain Adoption: An Integrative Framework. Strateg. Chang. 2020, 29, 501-515. [CrossRef]

55. Nandi, M.L.; Nandi, S.; Moya, H.; Kaynak, H. Blockchain Technology-Enabled Supply Chain Systems and Supply Chain Performance: A Resource-Based View. Supply Chain Manag. 2020, 25, 841-862. [CrossRef]

56. Yiu, N.C.K. Decentralizing Supply Chain Anti-Counterfeiting and Traceability Systems Using Blockchain Technology. Future Internet 2021, 13, 84. [CrossRef] 